\title{
THE IMPACT OF EXCHANGE RATE DEPRECIATION AND THE MONEY SUPPLY GROWTH ON INFLATION: THE IMPLEMENTATION OF THE THRESHOLD MODEL ${ }^{1}$
}

\author{
Rizki E. Wimanda ${ }^{2}$
}

\begin{abstract}
This paper investigates the impact of exchange rate depreciation and money growth to the CPI inflation in Indonesia. Using monthly data from 1980:1 to 2008:12, our econometric evidence shows that there are indeed threshold effects of money growth on inflation, but no threshold effect of exchange rate depreciation on inflation. However the threshold value for exchange rate depreciation is found at $8.4 \%$, and there is no significant difference between the coefficient both below and above the threshold value. Mean while, two threshold values are found for money growth, i.e. $7.1 \%$ and $9.8 \%$, and they are statistically different. The impact on inflation is high when money grows by up to $7.1 \%$, it is moderate when money grows by $7.1 \%$ to $9.8 \%$, and it is low when money grows by above $9.8 \%$.
\end{abstract}

JEL Classification: C22; E31; E51.

Keywords: Inflation, Threshold Effect; Indonesia

1 Extracted from Wimanda (2010), Doctoral Thesis, Chapter 4, "Threshold Effects of Exchange Rate and Money Growth on Inflation".

2 Researcher in Economy at Bank Indonesia, email: rizki@bi.go.id. 


\section{INTRODUCTION}

Concerns about inflation have been very intense since Indonesia adopted the inflation targeting in 2000. One of the important topics of the study is to examine the factors that cause inflation.

Wimanda (2010) ${ }^{3}$ found that inflation in Indonesia is significantly influenced by inflation expectations (backward-looking and forward-looking), output gap, exchange rate depreciation, and growth in money supply. Analysis of monthly samples from early 1980 until the end of 2008 shows that the formation of inflation expectations in Indonesia is still dominated by the backward-looking inflation expectations with a share of 0.7 , while the portion of forwardlooking inflation expectations is around 0.2. In his analysis,nWimanda also found that the impact of exchange rate is greater than the impact from the growth in money supply (M1). The analysis assumes that the impact of these two variables is linear, meaning that their impact is constant for each level of exchange rate depreciation and money supply growth.

By using the threshold model, this paper will test whether the impact of exchange rate and money supply growth on inflation is linear or not. And then to test whether there is a threshold value, how much the threshold value that can be identified, and the extent of the impact.

The systematic of this paper is as follows. Literature study will be discussed in the second chapter. Methodology and data will be discussed at the third part of this paper, while the estimation results and conclusions will be presented at the fourth and fifth chapter.

\section{THEORY}

\subsection{Pass-through of Exchange Rate}

One of the central issues in international economics is the pass-through of exchange rate which is defined as an impact of 1 percent of depreciation on the domestic inflation. In general, to test the exchange rate pass-through, we estimate at the following equation:

$$
\pi_{t}=\alpha+\gamma e_{t}+\delta x_{t}+\varepsilon_{t}
$$

where is the domestic inflation, is the depreciation of the exchange rate (nominal), and is the other control variables (in growth).

In general, the study of exchange rate pass-through can be divided into 3 groups.

3 In the 3rd chapter of Doctoral Thesis, "Determinants of Inflation and The Shape of Phillips Curve". 
The first group is the study of the impact of exchange rate on the import prices of certain industries, like as conducted by Bernhofen and Xu (1999) and Goldberg (1995). The second group is the study the impact of exchange rate on import prices in the aggregate, for example Hooper and Mann (1989) and Campa and Goldberg (2005). And the third group is the study of the impact of exchange rate on the CPI or WPI, for example, Papell (1994) and McCarthy (2000).

Although the literature on exchange rate pass-through is very plentiful, but empirical studies mostly focus on developed countries. A survey carried out by Menon (1995) showed that 48 studies on exchange rate pass-through specifically cover the United States and Japan. Similarly, Goldberg and Knetter (1997) mentioned that the study of exchange rate pass-through during the 1980s is dominated by the USA.

For OECD countries, the study of the impact of exchange rate pass-through on their import prices was conducted by Campa and Goldberg (2005). They found that exchange rate pass-through is partial, where import prices reflect 60 percent of exchange rate movements in the short term and nearly 80 percent in the long term. They also found that countries which have a low exchange rate volatility and low inflation have a low impact of exchange rates passthrough.

Using 71 countries data from 1979 to 2000, Choudhri and Hakura (2006) showed that there was a strong positive relationship between the exchange rate pass-through with the inflation average. Countries with low inflation tend to have a low exchange rates pass-through, and vice versa.

The relationship of exchange rate and inflation in Malaysia, Philippines, and Singapore was examined by Alba and Papper (1998) during the Q1 of 1979 Q1 until the Q2 of 1995. They found that the exchange rate pass-through for the Philippines is higher compared to Malaysia, while the exchange rate pass-through to Singapore was oppositely negative.

To support the argument of "fear of floating", Calvo and Reinhart (2000) also examined a number of developed and developing countries, including Malaysia and Indonesia. By using the monthly data from August 1997 through November 1999, they found the pass-through rate in Indonesia was 0.062 .

\subsection{Relationship between Money and Inflation}

The quantity theory and the exchange equation provide a useful framework to analyze empirically the relevance of money in the economy. The relationship of money and inflation can 
be derived from the money demand equation. The public wants to hold money to buy goods and services. If the price of goods and services rises, people tend to hold more money. The most important factor in the demand for money is the income. When incomes rise, people will tend to shop more. Higher expenditures are associated with more cash on hand. Thus, this relationship can be written as:

$$
\frac{M}{P}=k Y \text {, }
$$

where $M$ is the nominal money, $P$ is the price level based on the CPI or GDP deflator, $Y$ is the income and $k$ is the proportion factor. Equation (2) can be rewritten as

$$
P=\frac{1}{k} \frac{M}{Y}
$$

By assuming that the causality from $M$ to $P$ exists, equation (3) states that the quantity of money determines the price level, although money is not the only factor. For example, when income and other factors which are reflected by $k$ do not change, and when the quantity of money increases, the price level will increase.

Milton Friedman (1968) argues that inflation is a monetary phenomenon. Studies conducted by Lucas (1980), Dwyer and Hafer (1988), Friedman (1992), Barro (1993), McCandless and Weber (1995), Dewald (1998), Rolnick and Weber (1997) and others concluded that the changes in the quantity of money and price changes have a close relationship.

Dwyer and Hafer (1999) showed that the price level has a positive and proportional relationship to the quantity of money in America, Britain, Japan, Brazil, and Chile during the 20th century. They also showed that in the shorter term, 5 years, the relationship of money growth and inflation remains in force.

Empirical study of the relationship between money growth (M1 and $\mathrm{M} 2$ ) and the inflation in 160 countries was carried out by De Grauwe and Polan (2005). They showed that during the past 30 years, the relationship of money supply growth and inflation is still valid. However, after dividing the sample based on the rate of inflation, they showed that countries with low inflation (below 10\%), the relationship between both variables weakened. Conversely, the relationship was strong in the countries with high inflation rates. However, this study did not specify at what level of money supply will give a different effect on inflation. 


\subsection{Threshold Model Application}

Threshold model is a special case of complex statistical frameworks, such as mixture models, switching models, Markov-switching model, and smooth transition threshold model (Hansen, 1997).

Threshold model can be applied in many cases. For example, Galbraith (1996) conducted a study on the relationship betweennmoney and output. By using the data of US and Canada, he found that money has a strong influence on the output when the value of money growth is below certain threshold. This result is consistent with the proposition that the monetary policy has little impact or no impact at all on when the money growth is very high.

Khan and Senhadji (2001) investigated the relationshipnbetween the inflation andneconomic growth in 140 countries during the period of 1960 untiln1998. They argue thatninflation has a negative impact on the economy when inflation is above certain threshold values. In contrast, inflation has a positive impact on the economy when inflation is below the threshold value. They found that the threshold value for developed countries is 1-3 percent, and about 11-12 percent of threshold value for developing countries.

Threshold model is also used by Papageorgiou (2002) to evaluate the level of openness of the economy. Foster (2006) examined the relationship of export and economic growth for African countries. The evaluation of the fiscal deficit was also performed using the threshold models, for example for the case of USA (see Arestis, Cipollini and Fattouh, 2004) and Spain (see Bajo-Rubio, Diaz-Roldan and Esteve, 2004).

Meanwhile, the study of the threshold of exchange to the inflation and the threshold of money supply to inflation, to our knowledge, does not yet exist. Therefore, this study is conducted with the intention to complete the literature gap.

\section{METHODOLOGY}

\subsection{Empirical Model and the Estimation Technique}

This study is using the threshold modelnto answer the questions above. Threshold model is a special case of a complex statistical framework, such as mixture models, switching models, Markov-switching models, and smooth transition threshold models. In general, the threshold model can be written as follows:

$$
y_{t}=\beta_{j}{ }_{j} x_{t}+\delta_{1} z_{t} I\left(t h_{t} \leq \lambda\right)+\delta_{2} z_{t} I\left(t h_{t}>\lambda\right)+\mu_{t}
$$


where is the dependent variable, is the explanatory variable to be tested, is the vector of other explanatorynvariables, is the indicator function, is a threshold variable, and is the value of the threshold. In the equation above, the observations are divided into two regimes; depend on whether the threshold variable is smaller or larger than the value of.

To estimate the model, the threshold value and the value of slope parameter are estimated simultaneously. Hansen (1997) recommended seeking estimates of by finding the minimum valuenof sum of squared errors. To ensure that the number of observations in each regime is sufficient, the models are estimated for all the threshold value from the variable threshold between the 10th and 90th percentile.

Having found the threshold value, we need to test whether the value is statistically significant or not. In this case, whether the null hypothesis is to be rejected or accepted. One thing that may complicate is the non- identified threshold value in the null hypothesis. This implies that the classical test does not have a standard distribution, so that critical values cannot be obtained from the standard distribution tables.

This study follows Hansen $(1997,2000)$ in the search for multiple regimes in the data by using the exchange rate depreciation and the growth of $\mathrm{M} 1$ as the threshold variable. This method, which is based on the asymptotic distribution, will test the significance of regimes selected by the data.

In this study, we do not evaluate long-term relationship of the value of the exchange rate and the money supply to the price level, but we are more interested to see the short-term relationship of the exchange rate depreciation and the money supply growth to inflation. To examine the existence of a threshold effect of exchange rate depreciation on inflation, this hybrid model of Phillips curve will be estimated as follows:

$$
\begin{gathered}
\pi_{t}=c+\alpha_{1} \pi_{t-1}+\alpha_{2} \pi_{t+1}^{e}+\beta g a p_{t}+\gamma_{1}\left(1-d_{t}\right)\left[\left(e r_{t}\right) I\left(e r_{t}>e r^{*}\right)\right]+ \\
\gamma_{2} d_{t}\left[\left(e r_{t}\right) I\left(e r_{t} \leq e r^{*}\right)\right]+\theta m_{t}+\delta_{1} \text { crisis }+\delta_{2} \text { fuel }+\delta_{3} \text { fitri }+\varepsilon_{t} \\
\text { where, } \quad d_{t}= \begin{cases}1 & \text { if } e r_{t} \leq e r^{*} \\
0 & \text { if } e r_{t}>e r^{*}\end{cases}
\end{gathered}
$$

is inflation, $\pi_{t-1}$ is the backward-looking inflation expectations, $\pi_{t+1}^{e}$ is the forward-looking inflation expectations, gap $_{t}$ is the output gap, $e r_{t}$ is the depreciation of the exchange rate ${ }^{4}, \mathrm{er}^{*}$

4 The exchange rate is defined as the domestic currency per foreign currency. In this case we use Rp/USD. Thus, a negative er value means depreciation, while a positive er value indicates an appreciation 
is the threshold value of the exchange rate, $m_{t}$ is the growth ofnmoney supply (M1), crisis is the dummy variable to capture the financial crisis 1997-1998, fuel is a dummy variable to capture the fuel price surge in January 2005 and October 2005, and fitri is the dummy variable to capture the phenomenon of Idul Fitri.

We use instrumental variables (IV) estimators, which is the two-stage leastnsquares (TSLS). Thisnestimation methodncan overcome the endogeneity problems given that within the model used there is theninflation value in the future.

Model estimation is done by conditional least squares method which can be explained as follows:

For each threshold value $\mathrm{er}_{t}{ }^{*}$, the model is estimated through TSLS, to obtain the sum of squared residuals (SSR). The least squares estimation of $\mathrm{er}_{t}{ }^{*}$ is obtained by choosing the threshold value $e r_{t}{ }^{*}$ which has the minimum value of SSR. If we put all the threshold value observations into the vector, the compact notation of equation (2) then is as follows:

$$
y=x \beta_{e r}+\varepsilon, e r=\underline{e r}, \ldots . . \overline{e r}
$$

where $\beta_{e r}=\left(c \alpha_{1} \alpha_{2} \beta \gamma_{1} \gamma_{2} \theta \delta_{1} \delta_{2} \delta_{3}\right)^{\prime}$ ' is the vector of parameters, $y$ is the dependent variable, and $x$ is the matrix of the explanatory variables. It is noteworthy that the coefficient vector $\beta$ is indexed with er to show its dependence to the threshold value, which ranged from $\underline{e r}$ to $\overline{e r}$. We define $S_{1}(e r)$ as SSR with the threshold value of exchange rate depreciation on $e r$. The threshold estimation value $e r^{*}$ which is obtained is the threshold value with the minimum $S_{1}(e r)$ value, namely:

$$
e r^{*}=\operatorname{argmin}\left[S_{1}(e r), e r=\underline{e r}, \ldots ., \overline{e r}\right]
$$

Once the threshold value is obtained, we need to examine whether the threshold effect is statistically significant or not. In equation (2), to test the existence of the threshold effect, we need to test the null hypothesis, which is $H_{0}: \gamma_{1}=\gamma_{2}$. Hansen $(1997,2000)$ suggested the bootstrap method to simulate the asymptotic distribution of the likelihood ratio test from the $H_{0}$ as the following: 


$$
L R_{0}=n \frac{\left(S_{0}-S_{1}\right)}{S_{1}},
$$

where $S_{0}$ and $S_{1}$ is the SSR for $H_{0}: \gamma_{1}=\gamma_{2}$ and $H_{1}: \gamma_{1}=\gamma_{2}$. In other words, $S_{0}$ and $S_{1}$ is the SSR from the equation (2) without and with the threshold effects. Asymptotic distribution of $L R_{0}$ is nonstandard and dominate the distribution of $\chi^{2}$. The distribution of generally depends on the moments of sample, so that the critical values cannot be tabulated.

Given that $\gamma$ has not been identified, the asymptotic distribution of $L R_{0}$ is not $\chi^{2}$. Hansen (1997) showed that this can be approximated by using the following bootstrap procedure:

1. Set $\mu_{t}^{*}, t=1, \ldots ., \mathrm{n}$ as random number, drawn from a normal distribution whose mean is zero and whose variance is one i.e. $\mathrm{N}(0,1)$.

2. Set $y_{t}^{*}=\mu_{t}^{*}$.

3. By using the observation of $x_{t^{\prime}} t=1, \ldots ., \mathrm{n}$, regress $y_{t}^{*}$ at $x_{t}$ and find the residual variance

$\widetilde{\mathrm{\sigma}}_{\mathrm{n}}^{* 2}$ from the linear model, where.

$$
\tilde{\sigma}_{n}^{* 2}=\frac{1}{n} \sum_{t=1}^{n}\left(y_{t}^{*}-x_{t} \tilde{\beta}\right)^{2}
$$

4. By using the observation of $x_{t^{\prime}} t=1, \ldots ., \mathrm{n}$, regress $y_{t}^{*}$ at $x_{t}(\gamma)$ and find thenresidual variance $\widetilde{\mathrm{\sigma}}_{\mathrm{n}}^{* 2}(\gamma)$ from the threshold model, where

$$
\hat{\sigma}_{n}^{* 2}(\gamma)=\frac{1}{n} \sum_{t=1}^{n}\left(y_{t}^{*}-x_{t} \tilde{\beta}_{e r}\right)^{2}
$$

and $\gamma$ are the threshold value.

5. Calculate $F_{n}^{*}(\gamma)=n\left(\frac{\tilde{\sigma}_{n}^{* 2}-\hat{\sigma}_{n}^{* 2}(\gamma)}{\hat{\sigma}_{n}^{* 2}(\gamma)}\right)$.

6. Repeat step number 4 and 5 for the other $\gamma$.

7. Find $F_{n}^{*}=\sup _{\gamma \in \Gamma} F_{n}^{*}(\gamma)$.

8. Repeat step 1 to 7 over and over again.

Hansen (1997) also showed that the repetitive sampling from $F_{n}^{*}$ can be used as an approximation to the asymptotic distribution from $F_{n}$. The $p$-value of this test is to calculate the percentage of bootstrap samples whose the value of $F_{n}{ }^{*}$ exceeds $L R_{0}$ (see equation (5)). 
This study follows Hansen (2000) in forming the confidencenregionnfor $\mathrm{rr}^{*}$. The confidence intervalsnfor the threshold parameter inversion are built by inversing the asymptotic distribution of the likelihood ratio statistics. In this case, we tested null hypothesis $H_{0}: e r^{*}=e r$ by calculating the likelihood test as follows:

$$
L R(e r)=n \frac{S_{1}(e r)-S_{1}\left(e r^{*}\right)}{S_{1}\left(e r^{*}\right)},
$$

where $S_{1}(e r)$ and $S_{1}\left(e r^{*}\right)$ is the SSR from equation (2) with threshold $e r$ and $e r^{*}$. Define $c_{\xi}(\beta)$ as the $\beta$-level critical value for $\xi$ from Table 1 in Hansen (2000). Thus that defines

$$
\hat{\Gamma}=\left[e r: \operatorname{LR}(e r)<c_{\xi}(\beta)\right]
$$

Hansen (2000) shows that is asymptotically valid for $\beta$-level confidence at $e r$. To get a confidence interval, we plot the likelihood ratio $L R($ er $)$ with the threshold value (er), pull a straight line on $c_{\xi}(\beta)$, and mark the threshold value with the likelihood ratio whose value is under the critical value. It should be noted that the $L R(e r)$ will be equal to zero when $e r=e r^{*}$.

To test the existence of threshold effect of the money growth toward inflation, we use the same model, but we replace the exchange rate depreciation with the growth of money supply as the threshold variable. The model will be next estimated as follows:

$$
\begin{aligned}
\pi_{t}= & c+\alpha_{1} \pi_{t-1}+\alpha_{2} \pi_{t+1}^{e}+\operatorname{\beta gap}_{t}+\gamma e r_{t}+\theta_{1}\left(1-d_{t}\right)\left[\left(m_{t}\right) I\left(m_{t}>m^{*}\right)\right] \\
& +\theta_{2} d_{t}\left[\left(m_{t}\right) I\left(m_{t} \leq m^{*}\right)\right]+\delta_{1} \text { crisis }+\delta_{2} \text { fuel }+\delta_{3} \text { fitri }+\varepsilon_{t}
\end{aligned}
$$

where

$$
d_{t}= \begin{cases}1 & \text { if } m_{t} \leq m^{*} \\ 0 & \text { if } m_{t}>m^{*}\end{cases}
$$

Meanwhile the estimation and testing procedures for threshold growth of money supply is the same as the procedure above.

\subsection{Data}

We use CPI data, output gap, exchange rate, and M1. These data is obtained from Bank Indonesia (BI) and BPS. For the analysis, we use the monthly data from 1980 to 2008 (see Table 1). 


\begin{tabular}{c|l|c|c|c|}
\multicolumn{7}{|c}{ Table 1. Data } \\
No & \multicolumn{1}{|c|}{ Dat a } & Frequency & Period & Source \\
1 & CPI Inflation & Monthly & $1980: 1$ to $2008: 12$ & $\mathrm{BPS}$ and BI \\
2 & Output gap & Monthly & $1980: 1$ to $2008: 12$ & Author \\
3 & Exchange rate & Monthly & $1980: 1$ to $2008: 12$ & $\mathrm{BI}$ \\
4 & M1 & Monthly & $1980: 1$ to $2008: 12$ & $\mathrm{BI}$
\end{tabular}

\begin{tabular}{|c|c|c|c|c|c|c|}
\hline \multicolumn{7}{|c|}{$\begin{array}{l}\text { Table } 2 . \\
\text { Descriptive statistic of the data (year-on-year) }\end{array}$} \\
\hline \multirow{2}{*}{ D a t a } & \multicolumn{2}{|c|}{$1980-1997$} & \multicolumn{2}{|c|}{1998} & \multicolumn{2}{|c|}{$1999-2008$} \\
\hline & Mean & Std Dev & Mean & Std Dev & Mean & Std Dev \\
\hline CPI Inflation & 9.01 & 3.37 & 57.59 & 23.28 & 10.52 & 9.52 \\
\hline Exchange Rate Depreciation & -6.63 & 10.67 & -67.97 & 13.04 & 1.32 & 18.91 \\
\hline M1 Growth & 19.53 & 11.52 & 29.17 & 9.02 & 17.70 & 6.39 \\
\hline Output Gap - HPA & 0.19 & 3.39 & -11.76 & 1.97 & -2.31 & 3.25 \\
\hline Output Gap - Peak-to-Peak & -2.50 & 1.54 & -13.13 & 2.03 & -5.20 & 3.29 \\
\hline
\end{tabular}

\section{RESULT AND ANALYSIS}

\subsection{Threshold Effect on the Exchange Rate Depreciation}

Table 3 below shows the results of TSLS estimation of the equation (2) without the presence of threshold effect (by setting $\gamma_{1}=\gamma_{2}$ ). From this table we can see that all the parameters are significant, except for constant. By using the adjusted HP filter as a proxy in the calculation ofnpotential output, we find that the coefficient of exchange rate depreciation (yoy) is -0.050 and the coefficient of M1 growth is 0.021 . These resultnshows that in average the impact of exchange rate depreciation on inflation is still greater than the impact of the money supply growth.

\begin{tabular}{|l|c|c|c|c}
\multicolumn{5}{c}{ Table 3. } \\
\multicolumn{1}{|c|}{ Phillips Curve without Threshold } \\
Constant & Coef & Std. Error & t-Statistic & Prob. \\
Inflation & -0.148 & 0.141 & -1.051 & 0.294 \\
Inflation(1) & $(-1) 0.710$ & 0.042 & 17.078 & 0.000 \\
Output Gap (-9) & 0.225 & 0.058 & 3.911 & 0.000 \\
Exchange Rate Dep(-1) & 0.062 & 0.023 & 2.703 & 0.007 \\
M1 Growth(-2) & -0.050 & 0.009 & -5.223 & 0.000 \\
Dummy Crisis & 0.024 & 0.007 & 3.261 & 0.001 \\
Dummy Fuel & 1.293 & 0.539 & 2.400 & 0.017 \\
Dummy Fitri & 2.940 & 0.676 & 4.349 & 0.000 \\
\hline Adjusted R-squared & 0.548 & 0.213 & 2.567 & 0.011 \\
S.E. of regression & 0.991 & & & \\
SSR & 1.093 & & & \\
\end{tabular}




\begin{tabular}{|c|c|c|c|c|}
\hline & Coef & Std. Error & t-Statistic & Prob \\
\hline $\begin{array}{l}\text { Constant } \\
\text { Inflation(-1) } \\
\text { Inflation(1) } \\
\text { Output Gap(-9) } \\
\text { Exchange Rate Dep(-1)<=-8.4\% } \\
-8.4 \%>\text { Exchange Rate Dep(-1) } \\
\text { M1 Growth(-2) } \\
\text { Dummy Crisis } \\
\text { Dummy Fuel } \\
\text { Dummy Fitri }\end{array}$ & $\begin{array}{l}-0.169 \\
0.719 \\
0.211 \\
0.064 \\
-0.056 \\
-0.045 \\
0.026 \\
1.154 \\
2.973 \\
0.548\end{array}$ & $\begin{array}{l}0.144 \\
0.045 \\
0.062 \\
0.024 \\
0.012 \\
0.010 \\
0.008 \\
0.547 \\
0.693 \\
0.218\end{array}$ & $\begin{array}{l}-1.179 \\
16.071 \\
3.382 \\
2.703 \\
-4.652 \\
-4.567 \\
3.294 \\
2.109 \\
4.293 \\
2.516\end{array}$ & $\begin{array}{l}0.239 \\
0.000 \\
0.001 \\
0.007 \\
0.000 \\
0.000 \\
0.001 \\
0.036 \\
0.000 \\
0.012\end{array}$ \\
\hline $\begin{array}{l}\text { Adjusted R-squared } \\
\text { S.E. of regression } \\
\text { SSR }\end{array}$ & $\begin{array}{c}0.991 \\
1.116 \\
408.247\end{array}$ & & & \\
\hline
\end{tabular}

To estimate the threshold of exchange rate depreciation, we use equation (2). The threshold value in search has a value ranging from $-30 \%$ to $0 \%$. With an increase of $0.06 \%$ there are 500 candidates of the threshold value. From these 500 threshold values, the lowest SSR value is 408.25 , at the level of $8.4 \%$. This means that the threshold depreciation amounted to $8.4 \%$.

Table 4 shows the results of model estimation using the adjusted HP filter to calculate the potential output. From the table we can see that the impact of exchange rate depreciation on inflation, when the level of depreciation is greater than or equal to $8.4 \%$, is for 0.056 , while the impact, when the exchange rate depreciation rate is below $8.4 \%$, is 0.045 . Both coefficients above are significant at the level of $1 \%$.

The horizontal line in Figure 1 shows the $90 \%$ of confidence interval. The area below the horizontal line forms the region of acceptance. The $L R(g)$ statistic will be nil at the optimal threshold. From the figure we can see that the confidence interval for the threshold exchange rate is too wide. The area below the line where $L R(g)=5.94^{5}$ has the value ranging from $23.52 \%$ to $-2.64 \%$. This shows that the estimation of threshold value effect for the exchange rate depreciation isnnot too accurate.

To test whether there is a difference between a linear and a threshold model, we performed 1000 times bootstrapping. We followed the procedure suggested by Hansen (1997) to yield the critical value.

5 This is the critical value for $90 \%$ confidence interval from Table 1 Hansen (2000). 


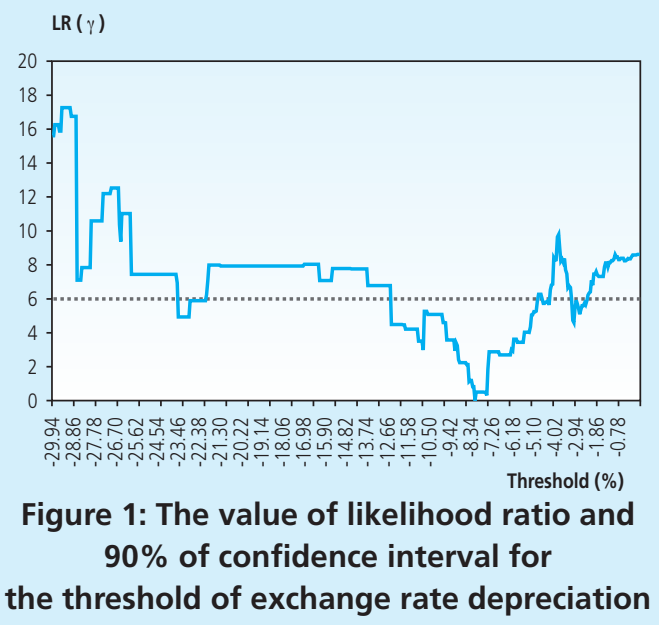

It was found that most of the $F_{\text {sup }}$ are superior to the value of $F_{o}$, which is -12.12, where the $p$-value is 0.957 . This shows that we cannot reject the null hypothesis where $\gamma_{1}=\gamma_{2}$. Thus, it can be concluded that there was no significant difference in the impact of the exchange rate depreciation on inflation at the level below and above the threshold. In other words, the impact of exchange rate depreciation on inflation is linear, that is equal to $0.05 \%$ for every $1 \%$ of depreciation rate.

As for the robustness check, we use various alternative models, which are the model by that use the peak-to-peak output gap and model by adopting asymmetric ties between inflation and output, which is the L-shaped function ${ }^{6}$. This alternative model can be seen in Table 5 .

Table 6 shows the estimation results with and without the threshold effect. From this table we can see that the coefficient of the exchange rate depreciation is below or equal to its

\section{Table 5.}

\section{Alternative model alternative for the threshold of exchange rate depreciation}

\begin{tabular}{c|c|c|c} 
Model & Output Gap Measurement & Output Gap Function & ER Dep. Threshold \\
1 & Peak-to-Peak & Linear & No \\
2 & Peak-to-Peak & Linear & Yes \\
3 & Adjusted HP Filter & Non-Linear & No \\
4 & Adjusted HP Filter & Non-Linear & Yes
\end{tabular}

6 According to the results of the 3rd chapter of the Doctoral Thesis of Wimanda (2010), the Phillips curve in Indonesia is more suited to be modeled with the L-shape function with wall parameter of $8.5 \%$. This function is actually a parabolic function where the impact of the output gap to inflation would be enormous if the output gap is close to $8.5 \%$. 


\begin{tabular}{|c|c|c|c|c|}
\hline Variable & Model-1 & Model-2 & Model-3 & Model-4 \\
\hline Constant & $\begin{array}{c}0.007 \\
(0.186)\end{array}$ & $\begin{array}{c}0.011 \\
(0.192)\end{array}$ & $\begin{array}{c}-0.325 * * * \\
(0.122)\end{array}$ & $\begin{array}{c}-0.358 * * * \\
(0.127)\end{array}$ \\
\hline Inflation $(-1)$ & $\begin{array}{l}0.714^{* * *} \\
(0.043)\end{array}$ & $\begin{array}{l}0.730 * * * \\
(0.048)\end{array}$ & $\begin{array}{l}0.694^{* * *} \\
(0.037)\end{array}$ & $\begin{array}{l}0.705^{* * *} \\
(0.041)\end{array}$ \\
\hline Inflation(1) & $\begin{array}{l}0.223 * * * \\
(0.059)\end{array}$ & $\begin{array}{l}0.199 * * * \\
(0.067)\end{array}$ & $\begin{array}{l}0.249 * * * \\
(0.051)\end{array}$ & $\begin{array}{l}0.233 * * * \\
(0.056)\end{array}$ \\
\hline Output Gap Linear (-9) & $\begin{array}{l}0.071 * * \\
(0.03)\end{array}$ & $\begin{array}{c}0.081 * * \\
(0.032)\end{array}$ & & \\
\hline Output Gap Non-Linear(-9) & & & $\begin{array}{l}0.0003 * * \\
(0.00016)\end{array}$ & $\begin{array}{l}0.0004 * * \\
(0.00017)\end{array}$ \\
\hline Exchange Rate Dep(-1) & $\begin{array}{l}-0.048 * * * \\
(0.009)\end{array}$ & & $\begin{array}{l}-0.047 * * * \\
(0.009)\end{array}$ & \\
\hline Exchange Rate Dep $(-1)<=$ Threshold & & $\begin{array}{l}-0.057 * * * \\
(0.013)\end{array}$ & & $\begin{array}{l}-0.054 * * * \\
(0.011)\end{array}$ \\
\hline Threshold < Exchange Rate Dep(-1) & & $\begin{array}{l}-0.041 * * * \\
(0.009)\end{array}$ & & $\begin{array}{l}-0.041 * * * \\
(0.009)\end{array}$ \\
\hline M1 Growth(-2) & $\begin{array}{l}0.027 * * * \\
(0.008)\end{array}$ & $\begin{array}{l}0.030 * * * \\
(0.009)\end{array}$ & $\begin{array}{l}0.027 * * * \\
(0.008)\end{array}$ & $\begin{array}{l}0.031 * * * \\
(0.008)\end{array}$ \\
\hline Dummy Crisis & $\begin{array}{l}1.228 * * \\
(0.536)\end{array}$ & $\begin{array}{l}1.154 * * \\
(0.547)\end{array}$ & $\begin{array}{c}0.652 \\
(0.405)\end{array}$ & $\begin{array}{c}0.462 \\
(0.422)\end{array}$ \\
\hline Dummy Fuel & $\begin{array}{c}2.944 * * * \\
(0.683)\end{array}$ & $\begin{array}{c}2.973 * * * \\
(0.693)\end{array}$ & $\begin{array}{c}2.772 * * * \\
(0.648)\end{array}$ & $\begin{array}{c}2.805 * * * \\
(0.665)\end{array}$ \\
\hline Dummy Fitri & $\begin{array}{c}0.551 * * \\
(0.215)\end{array}$ & $\begin{array}{c}0.548 * * \\
(0.218)\end{array}$ & $\begin{array}{c}0.554 * * * \\
(0.208)\end{array}$ & $\begin{array}{c}0.554 * * * \\
(0.213)\end{array}$ \\
\hline Adjusted R-squared & 0.991 & 0.991 & 0.992 & 0.991 \\
\hline S.E. of regression & 1.103 & 1.116 & 1.066 & 1.091 \\
\hline SSR & 400.161 & 408.247 & 373.986 & 390.569 \\
\hline Threshold ER & & -8.40 & & -8.40 \\
\hline$p$-value & & 0.999 & & 0.966 \\
\hline
\end{tabular}

Remarks:

- The number between parentheses is the error standard.

- ***,**, and * indicate the significance level at the level of $1 \%, 5 \%$, and $10 \%$.

threshold value $\left(\gamma_{1}\right)$. And above its threshold value in model 2 and model $4\left(\gamma_{2}\right)$ the value is negative and significant. We found that the threshold value is equal to the threshold value on the previous model, at the level of $-8.4 \%$. Coefficient value $\gamma_{1}$ of is in the range of -0.054 to 0.057 , while the coefficient value of $\gamma_{2}$ is relatively the same at -0.041 .

After performing as much as 1,000 times bootstrapping, model 2 and model 4 yield the same conclusion with the main model. Overall, from the bootstrap test statistics, there is not any statistical significance on these variables. The $p$-values range between 0966 and 0999 . This implies that there is no significant difference between the impact of exchange rate depreciation on inflation, above and below its threshold value. 
If we compare model 1 and model 2, as well as model 3 and model 4, we can see that the value of SSR for the threshold model is greater than the value of the SSR on the linear model. This confirms the above conclusion.

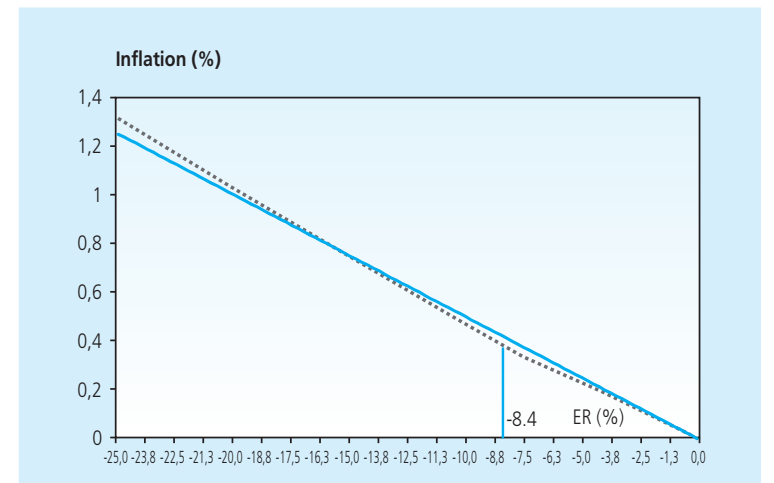

Figure 2.The impact of exchange rate depreciation on the inflation: an illustration

Figure 2 above illustrates the impact of exchange rate depreciation on inflation. From this picture, we can see that the slope in solid blue line is the same for every point. This linear impact (solid blue line) is more preferable than the non-linear impact of (dashed brown line).

\subsection{Threshold Effect on the Money Growth}

To estimate the threshold valuenfor the moneynsupply growth, we use equation (8) with the output gap, which is calculated based on thenadjusted HP filter. This search for the threshold value starts from $0 \%$ to $40 \%$, with an increase of 0.08 . This means that there are approximately 500 candidates for the threshold value. We found that the threshold value for the M1 growth was $9.84 \%^{7}$.

Table 7 shows thenestimation results of threshold with using the adjusted HP filter as a measurement of the output gap. Given that the results of the main variables are quite robust, that all coefficients are statistically significant, we can then immediately analyze its threshold results. From the table, the coefficient of the money supply growth, below or equal to $9.84 \%$ $\left(\theta_{1}\right)$, is 0.099 , while the coefficient of the money supply growth above $9.84 \%\left(\theta_{2}\right)$ is 0.032 . Both coefficients are significant at the level of $1 \%$.

7 This value give the smallest SSR. 


\begin{tabular}{|c|c|c|c|c|}
\hline & Coef & Std. Error & t-Statistic & Prob. \\
\hline $\begin{array}{l}\text { Constant } \\
\text { Inflation(-1) } \\
\text { Inflation(1) } \\
\text { Output Gap(-9) } \\
\text { Exchange Rate Dep(-1) } \\
\text { M1 Growth(-2)<=9.84\% } \\
9.84 \%<\text { M1 Growth(-2) } \\
\text { Dummy Crisis } \\
\text { Dummy Fuel } \\
\text { Dummy Fitri }\end{array}$ & $\begin{array}{l}-0.361 \\
0.695 \\
0.241 \\
0.053 \\
-0.047 \\
0.099 \\
0.032 \\
1.229 \\
2.983 \\
0.583\end{array}$ & $\begin{array}{l}0.150 \\
0.039 \\
0.054 \\
0.022 \\
0.009 \\
0.030 \\
0.008 \\
0.516 \\
0.656 \\
0.207\end{array}$ & $\begin{array}{l}-2.405 \\
17.947 \\
4.468 \\
2.455 \\
-5.257 \\
3.341 \\
3.877 \\
2.384 \\
4.549 \\
2.821\end{array}$ & $\begin{array}{l}0.017 \\
0.000 \\
0.000 \\
0.015 \\
0.000 \\
0.001 \\
0.000 \\
0.018 \\
0.000 \\
0.005\end{array}$ \\
\hline $\begin{array}{l}\text { Adjusted R-squared } \\
\text { S.E. of regression } \\
\text { SSR }\end{array}$ & $\begin{array}{c}0.992 \\
1.057 \\
366.404\end{array}$ & & & \\
\hline
\end{tabular}

This result impliesnthat there are differences in the impact of the M1 growthnon inflation, nabove or below its threshold value at $9.84 \%$. As an illustration, shall $\mathrm{M} 1$ grow by $5 \%$ this month, and then there will be an additional inflation of $0.5 \%$ in two months to come. Meanwhile, shall M1 grow 10\% this month; there will be then an additional average inflation of $0.98 \%$ within 2 months.

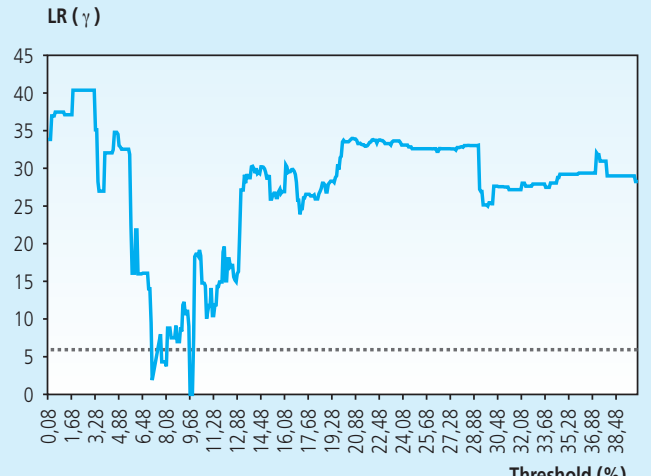

Figure 3: The value of likelihood ratio and $90 \%$ confidence interval for the threshold of M1 growth: first point

Once the threshold value is identified, the next important question is how accurate are these estimates. This requires the calculation of the confidence regions around the threshold value. Figure 3 illustrates the value of likelihood ratio and the threshold value, as well as 90\% 
confidence intervals. As explained above, the confidence region is calculated by taking the values of $\mathrm{M} 1$ growth where the value of $L R(M 1)$ is below the horizontal line. From this figure it shows that the confidence interval for the money growth is quite narrow, around $7.12 \%$ $10 \%$. This indicates that the estimated threshold value is accurate enough.

The next step is to test whether the threshold value exists by performing bootstrapping. By generating new samples, repeated by 1,000 times for the percentile estimation of the asymptotic null distribution $F_{n}{ }^{*}$, we find that the $p$-value is 0.001 . Thus, the null hypothesis (linear model) can be rejected and it concludes that there is a threshold value for the M1 growth.

After finding the first threshold value, we seek the possibility of another threshold value. We can find three regimes at the same time, but this would be very inefficient in terms of computation time. Chong (1994) and Bai (1997) showed that the sequential estimation is consistent, so that it can avoid the problem of calculation. This means that we can fix the first threshold figure, en then seek the second one by assuming that the first threshold is already fixed.

After finding the first threshold value, we seek the possibility of another threshold value. We can find three regimes at the same time, but this way is very inefficient in terms of computation time. Chong (1994) and Bai (1997) showed that the sequential estimation is consistent, so that it can avoid the problem of calculation. This means we can make the fix-it figures that the first threshold then seek a second threshold value by assuming that the first threshold has been fixed.

We begin by considering the possibility of another threshold value between $9.84 \%$ and $40 \%$. With a value addition by 0.075 there are 400 candidates for the threshold value. It is found that the smallest SSR is when the threshold is at $17.13 \%$. This means that $17.3 \%$ is the second threshold candidate. TSLS estimation results can be seen in Table A (see Appendix). Although these entire $\mathrm{M} 1$ growth coefficients are significant at level of $1 \%$, but after conducting the bootstrapping, we found the $p$-value at 0.177 which is slightly larger than $10 \%$. Thus, the null hypothesis from these 2 threshold regime cannot be rejected. In other words, the relationship between inflation and the M1 growth is linear by the time M1 grows above $9.84 \%$.

The next effort to search the threshold candidate is between $0 \%$ and $9.84 \%$. We selected 350 values and found the minimum SSR at the point of $7.08 \%$. TSLS Estimation results with 2 thresholds: $9.84 \%$ and 7:08\% can be seen in Table 8. From the table we can note that the coefficient of M1 growth, when it grows under 7.08\%, is 0.146; when it grows between $7.08 \%$ and $9.84 \%$, the coefficient is 0.088 , and when it grows over than $9.84 \%$, the coefficient 


\begin{tabular}{l|c|c|c|c}
\multicolumn{5}{c}{ Table 8. } \\
\multicolumn{1}{|c}{ Phillips curve with the threshold of M1 growth: second point } \\
\hline Constant & Coef & Std. Error & t-Statistic & Prob. \\
Inflation(-1) & -0.404 & 0.151 & -2.671 & 0.008 \\
Inflation(1) & 0.687 & 0.038 & 18.160 & 0.000 \\
Output Gap(-9) & 0.252 & 0.053 & 4.772 & 0.000 \\
Exchange Rate Dep(-1) & 0.049 & 0.021 & 2.318 & 0.021 \\
M1 Growth(-2)<=7.08\% & -0.045 & 0.009 & -5.152 & 0.000 \\
7.08\% $<$ M1 Growth(-2)<=9.84\% & 0.146 & 0.049 & 2.997 & 0.003 \\
9.84\% $<$ M1 Growth(-2) & 0.088 & 0.030 & 2.922 & 0.004 \\
Dummy Crisis & 0.033 & 0.008 & 4.003 & 0.000 \\
Dummy Fuel & 1.151 & 0.506 & 2.276 & 0.024 \\
Dummy Fitri & 2.954 & 0.645 & 4.580 & 0.000 \\
\hline Adjusted R-squared & 0.602 & 0.204 & 2.951 & 0.003 \\
S.E. of regression & 0.992 & & & \\
SSR & 1.041 & & & \\
\end{tabular}

decreases to 0.033 . All of the above coefficients are significant at the level of $1 \%$. This shows that a higher M1 growth of M1, will cause less impact on the inflation.

Figure 4 shows that the minimum likelihood ratio is found at the threshold point of $7.08 \%$. Its $90 \%$ confidence interval is quite narrow, which is from $6.94 \%$ to $8.04 \%$. This indicates that $7.08 \%$ is a potential candidate for the second threshold.

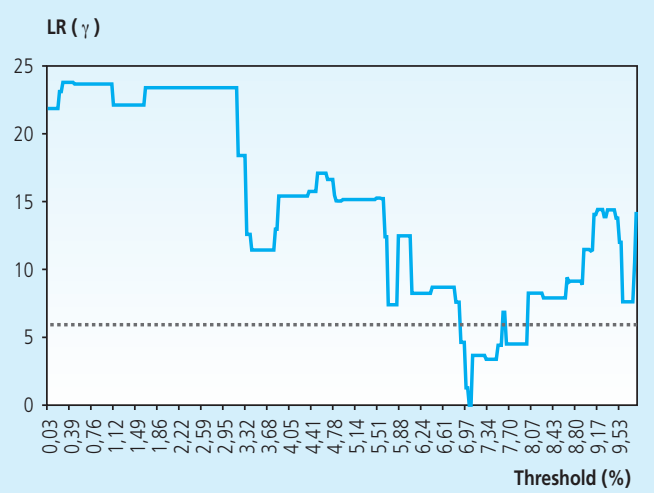

Figure 4: The value of likelihood ratio and $90 \%$ confidence interval for the threshold growth M1: second point

A formal test is carried out by bootstrapping samples. By replicating samples and repeating it by 1,000 times, we find the p-value at 0.004 . Thus, we reject the null hypothesis of the 2 regimes. Based on these tests, we conclude that there are 3 threshold regimes for the M1 growth. 
Next we look for another threshold value candidate between $0 \%$ and $7.08 \%$. With an addition of $0.028 \%$, we evaluated 250 candidates. Of the 250 these candidates, we found that the SSR value is the lowest at the point of $4.93 \%$.

Table B (see Appendix) presents the TSLS estimation result with four regimes. All coefficients are significant, except the coefficient for M1 growth from 0\% to $4.93 \%$ ( $p$-value $=0273$ ). The formal testing through bootstrapping produces $p$-value by 0.191 . This indicates that the relationship of inflation with the M1 growth is linear when M1 grows between 0\% and $7.12 \%$. Given that the third threshold is not significant, it is impossible to separate further the samples.

\begin{tabular}{c|l|c|c}
\multicolumn{5}{c}{ Alternative model for the threshold of M1 growth } \\
Model & $\begin{array}{l}\text { Output Gap Measurement } \\
\text { Output Gap Function }\end{array}$ & M1 Threshold \\
5 & $\begin{array}{l}\text { Peak-to-Peak } \\
6\end{array}$ & $\begin{array}{l}\text { Peak-to-Peak } \\
7\end{array}$ & Adjusted HP Filter \\
8 & Adjusted HP Filter & Linear & No \\
\end{tabular}

As for robustness check, again we use a variety of models with the difference that lies in the measurement of the output gap and the non-linear Phillips curve. Table 9 shows the difference.

As shown in Table 10, these empirical results yield some interesting results. First, all coefficients, except the constant and dummy variables for the crisis on some models, are significant. Second, the estimation of the threshold value is the same, $9.84 \%$ and $7.08 \%$. Third, the coefficient of the threshold effect is somewhat different, yet the difference is abysmal. The coefficient of M1 growth when growing under $7.08 \%$ ranges from 0.156 to 0.160; coefficient of M1 growth when growing between $7.08 \%$ and $9.84 \%$ ranges from 0.094 to 0.096 , and the coefficient of M1 growth when growing over $9.84 \%$ ranges from 0.035 to -0037 .

Given that all the $p$-values of the bootstrapping are less than $1 \%$, then we can reject the null hypothesis for the two regimes and prefer to the three regimes. In addition, when compared to the SSR value to the threshold model (model 6 and model 8) and the SSR value on the linear model (model 5 and model 7), we found that the threshold model is better than the linear model. 


\begin{tabular}{|c|c|c|c|c|}
\hline Variable & Model-1 & Model-2 & Model-3 & Model-4 \\
\hline Constant & $\begin{array}{l}0.062 \\
(0.187)\end{array}$ & $\begin{array}{l}-0.284 \\
(0.183)\end{array}$ & $\begin{array}{c}-0.279 * * \\
(0.12)\end{array}$ & $\begin{array}{c}-0.559 * * * \\
(0.137)\end{array}$ \\
\hline Inflation & $\begin{array}{l}(-1) 0.714 * * * \\
(0.043)\end{array}$ & $\begin{array}{l}0.689 * * * \\
(0.039)\end{array}$ & $\begin{array}{l}0.694^{* * *} \\
(0.037)\end{array}$ & $\begin{array}{l}0.672 * * * \\
(0.034)\end{array}$ \\
\hline Inflation(1) & $\begin{array}{c}0.223 * * * \\
(0.059)\end{array}$ & $\begin{array}{c}0.250 * * * \\
(0.053)\end{array}$ & $\begin{array}{l}0.251 * * * \\
(0.051)\end{array}$ & $\begin{array}{l}0.273^{* * *} \\
(0.047)\end{array}$ \\
\hline Output Gap Linear(-9) & $\begin{array}{c}0.074^{* *} \\
(0.03)\end{array}$ & $\begin{array}{l}0.060 * * \\
(0.028)\end{array}$ & & \\
\hline Output Gap Non-Linear(-9) & & & $\begin{array}{l}0.000334 * * \\
(0.000161)\end{array}$ & $\begin{array}{l}0.00033^{* *} \\
(0.000153)\end{array}$ \\
\hline Exchange Rate Dep(-1) & $\begin{array}{c}-0.048 * * * \\
(0.009)\end{array}$ & $\begin{array}{c}-0.043^{* * *} \\
(0.008)\end{array}$ & $\begin{array}{c}-0.047 * * \star \\
(0.009)\end{array}$ & $\begin{array}{c}-0.042 * * * \\
(0.008)\end{array}$ \\
\hline M1 Growth(-2) & $\begin{array}{c}0.024^{* * *} \\
(0.007)\end{array}$ & & $\begin{array}{l}0.026^{* * *} \\
(0.007)\end{array}$ & \\
\hline M1 Growth $(-2)<=2$ nd Threshold & & $\begin{array}{l}0.156 * * * \\
(0.049)\end{array}$ & & $\begin{array}{l}0.160 * * * \\
(0.048)\end{array}$ \\
\hline 2nd Threshold $<$ M1 Growth(-2) $<=1$ st Threshold & & $\begin{array}{l}0.096 * * * \\
(0.031)\end{array}$ & & $\begin{array}{l}0.094^{* * *} \\
(0.03)\end{array}$ \\
\hline 1st Threshold < M1 Growth(-2) & & $\begin{array}{c}0.035 * * * \\
(0.008)\end{array}$ & & $\begin{array}{l}0.037 * * * \\
(0.008)\end{array}$ \\
\hline Dummy Crisis & $\begin{array}{l}1.235^{\star *} \\
(0.539)\end{array}$ & $\begin{array}{l}1.122 * * \\
(0.503)\end{array}$ & $\begin{array}{c}0.644 \\
(0.406)\end{array}$ & $\begin{array}{c}0.633 \\
(0.386)\end{array}$ \\
\hline Dummy Fuel & $\begin{array}{l}2.929 * * * \\
(0.685)\end{array}$ & $\begin{array}{l}2.968 * * * \\
(0.65)\end{array}$ & $\begin{array}{l}2.752 * * * \\
(0.649)\end{array}$ & $\begin{array}{l}2.819 * * * \\
(0.619)\end{array}$ \\
\hline Dummy Fitri & $\begin{array}{l}0.550 * * \\
(0.216)\end{array}$ & $\begin{array}{l}0.608 * * * \\
(0.205)\end{array}$ & $\begin{array}{l}0.553 * * * \\
(0.209)\end{array}$ & $\begin{array}{l}0.611 * * * \\
(0.199)\end{array}$ \\
\hline Adjusted R-squared & 0.991 & 0.992 & 0.992 & 0.992 \\
\hline S.E. of regression & 1.107 & 1.045 & 1.070 & 1.014 \\
\hline & 403.146 & 357.419 & 376.347 & 336.461 \\
\hline 1st Threshold & & 9.84 & & 9.84 \\
\hline 2nd Threshold & & 7.08 & & 7.08 \\
\hline$p$-value & & 0.005 & & 0.005 \\
\hline
\end{tabular}

Remarks:

- The number within the parentheses is the error standard.

- $* * *, * *$, and * indicates the significance level on the level of $1 \%, 5 \%$, and $10 \%$.

From the test results and analysis above, these empirical results provide strong evidence that the relationship of $\mathrm{M} 1$ growth and inflation can be described by three regimes. Figure 5 illustrates this relationship. From the picture, we can see that the slope of the solid brown line when M1 grows up to $7.1 \%$ is steeper than the line when M1 grows between $7.1 \%-9.8 \%$. Similarly, when M1 grows more than $9.8 \%$, the slope becomes more gently sloping. 


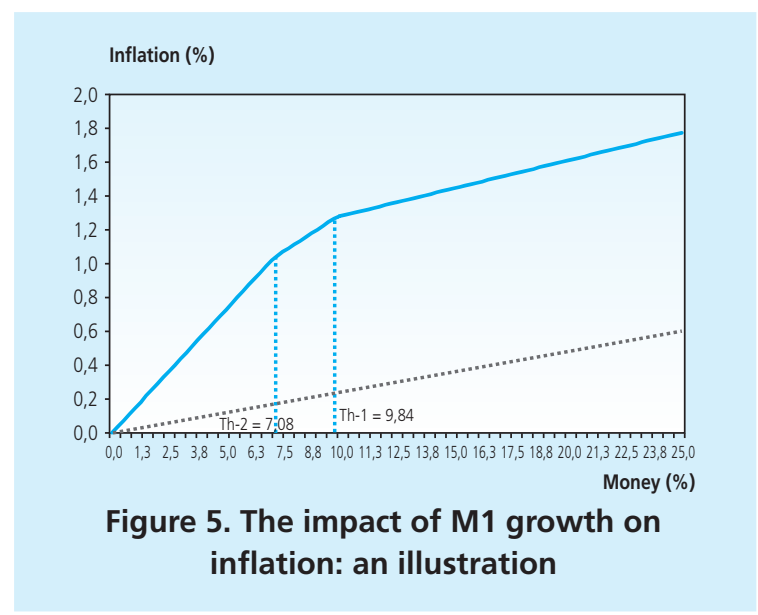

\section{CONCLUSION}

This paper contributes to existing literature in which the threshold determination is done by using the techniques developed by Hansen $(1997,2000)$. Compared with the definition of threshold conducted arbitrarily, this technique provides some benefits where the threshold value can be determined by the characteristics of the data itself. Furthermore, this technique allows detecting the possibility of other threshold value. If there is only one threshold value fixed one, while in fact there are more than one, then the value of the coefficient can be under/ over estimate.

This paper provides a comprehension of the threshold effect of exchange rate depreciation and the growth of money supply (M1) toward the inflation in Indonesia. By using the monthly data from 1980:01 to 2008:12, this model provides strong evidence that there is a threshold effect from the money supply growth on inflation, but it does not find any threshold effect between the exchange rate depreciation and inflation.

All experiments carried out as much as 1,000 times. By using two different output gap measurements, which are the adjusted HP filter and the peak-to-peak method, and two types of inflation-output relationship, which are the linear and L-shape function, our conclusions remain the same. Threshold value of the exchange rate depreciation is $8.4 \%$. However, the coefficient from the exchange rate depreciation at the rate below $8.4 \%()$ and the coefficient of the exchange rate above $8.4 \%$ () does not differ much. The F-test gives a conclusion that there is no significant difference between and $\gamma_{2}$. Thus, the impact of exchange rate depreciation on inflation is linear for all depreciation rates (which is 0.05 ).

For the growth of money supply, we find the evidence that there are two threshold values, at $7.1 \%$ and $9.8 \%$. The F-test concludes that the effect of these three regimes is 
significantly different. This empirical result indicates that the impact of money supply growth on inflation is not linear. The biggest impact on money supply growth is between $0 \%$ and $7.1 \%$ (i.e. 0.15 ), moderate impact occurs when the money supply to grow between $7.1 \%$ and $9.8 \%$ (i.e. 0:09), and the lowest impact is when the money supply grows above $9.8 \%$ (i.e. 0.03). As the money supply grows higher, the impact on inflation will be reduced.

In general, our findings are in line with Galbraith's (1996) who studied the relationship between money supply with output. He discovered that money has a great impact on output if the money supply grows below its threshold value as compared when it grows above the threshold. These findings are consistent with the proposition that monetary policy has little or even no effect when the money supply grows very highly.

These findings provide the conclusion that the impact of money supply on inflation when the money supply grows below $9.8 \%$ will be greater than the impact of exchange rate depreciation on inflation. This conclusion is different from previous studies that did not include the threshold effect, where the impact of exchange rate depreciation on inflation is greater than the money supply growth at every level.

Although the impact of exchange rate depreciation on inflation is linear, it does not mean that, as the monetary authority, Bank Indonesia can override the depreciation rate because of the impact is moderate. Furthermore, this study suggests that Bank Indonesia should consider the growth of money supply, in this case M1, considering that the impact of M1 is large enough at the time it is at a level below the its threshold value. Although the impact of M1 growth on inflation is not linear with a smaller impact at the time the M1 growth is over its threshold value, this study does not suggest leaving M1 to grow rapidly.

Our findings above are based on the methodology proposed by Hansen (1997, 2000). However, this study does not explain why higher money supply growth gives a mild impact on inflation. Thus, further studies in the future in this area are needed to explain the reason for this asymmetric effect.

The analysis above is based on partial analysis, using a single equation model, despite the fact that the exchange rate and the money supply are not independent. The use of a more complex model where the exchange rate and money supply are used as endogenous variables to evaluate the threshold value, as found in this study, would be an interesting study. It is worth to be reserved for further study. 


\section{REFERENCES}

Alba, J. D., Papell, D. (1998), 'Exchange Rate Determination and Inflation in Southeast Asian Countries', Journal of Development Economics, 55(2), 421-437.

Arestis, P., Cipollini, A., Fattouh, B. (2004), 'Threshold Effect in the U.S. Budget Deficit', Economic Inquiry, 42(2), 214-222.

Bai, J. (1997), 'Estimating Multiple Breaks One at a Time', Econometric Theory, 13, 315-52.

Bajo-Rubio, O., Diaz-Roldan, C., Esteve, V. (2004), 'Searching for Threshold Effects in the Evolution

of Budget Deficits: An Application to the Spanish Case', Economics Letters, 82, 239-243.

Barro, R. J. (1993), Macroeconomics, 4th edition, New York: Wiley

Bernhofen, D. M., Xu, P. (2000),n'Exchange Rates and Market Power: Evidence from the Petrochemical Industry', Journal of International Economics, 52, 283-297.

Calvo, G. A., Reinhart, C. M. (2000), 'Fixing for Your Life', NBER Working Paper, 8006.

Campa, J. M., Goldberg, L. S. (2005), 'Exchange Rate Pass-Through into Import Prices: A Macro or Micro Phenomenon?', Review of Economics and Statistics, 87(4), 679-690.

Chong, T.T.L. (1994), 'Consistency of Change-Point Estimators when the Number of ChangePoints in Structural Change Models is Underspecified', Working Paper, Chinese University of Hong Kong.

Choudhri, E. U., Hakura, D. S. (2006), 'Exchange Rate Pass-through to Domestic Prices: Does the Inflationary Environment Matter?', Journal of International Money and Finance, 25, 614-639.

De Grauwe, P., Poland, M. (2005), 'Is Inflation always and Everywhere a Monetary Phenomenon?', Scandinavia Journal of Economics, 107(2), 239-259.

Dewald, W. G. (1998), 'Money Still Matters', Federal Reserve Bank of St. Louis Review, 80, 1324.

Dwyer, G. P., Hafer, R. W. (1988), 'Is Money Irrelevant?', Federal Reserve Bank of St. Louis Review, (May/June), 3-17.

Dwyer, G. P., Hafer, R. W. (1999),n'Are Money Growth and Inflation Still Related?', Economic Review, Federal Reserve Bank of Atlanta, Second Quarter.

Foster, N. (2006), 'Export, Growth and Threshold Effects in Africa', Journal of Development Studies, 42(6), 1056-1074. 
Friedman, M. (1968), 'The Role of Monetary Policy', American Economic Review, 58(1): 1-17.

Friedman, M. (1992), Money Mischief: Episodes in Monetary History, New York: Harcourt Brace Jovanovich

Galbraith, J.W. (1996), 'Credit Rationing and Threshold Effects in the Relation between Money and Output', Journal of Applied Econometrics, 11(4), 419-429.

Goldberg, P. K. (1995), 'Product Differentiation and Oligopoly in International Markets: the Case of the U.S. Automobile Industry', Econometrica, 63(4), 891-951.

Goldberg, P. K., Knetter, M. (1997), 'Goods Prices and Exchange Rates: What Have We Learned?', Journal of Economic Literature, 35, 1243-1272.

Lucas, R. E. (1980), 'Two Illustrations of the Quantity Theory of Money', American Economic Review, 70, 1005-14.

Hansen, B.E. (1997), 'Inference in TAR Models', Studies in Nonlinear Dynamics and Econometrics, 2(1), 1-14.

Hansen, B.E. (2000), 'Sample Splitting and Threshold Estimation', Econometrica, 68(3).

Hooper, P., Mann, C. L. (1989), 'Exchange Rate Pass-Through in the 1980s: the Case of U.S.

Imports of Manufactures', Brookings Papers of Economic Activity, 1.

Khan, M. S., Senhadji, A.S. (2001), 'Threshold Effect in the Relation between Inflation and Growth', IMF Staff Paper, 48(1).

McCandless, G. T., Weber, W. E. (1995), 'Some Monetary Facts', Federal Reserve Bank of Minneapolis Quarterly Review, 19(3), 2-11.

McCarthy, J. (2000), 'Pass-Through of Exchange Rates and Import Prices to Domestic Inflation in Some Industrialized Economies', Federal Reserve Bank of New York Staff Report, 3.

Menon, J. (1995), 'Exchange Rate Pass-Through', Journal of Economic Surveys, 9(2), 197-231. Papageorgiou, C. (2002), 'Trade as Threshold Variable for Multiple Regimes', Economics Letters, 77, 85-91.

Papell, D. H. (1994), 'Exchange Rates and Prices: An Empirical Analysis','International Economic Review, 35(2), 397-410.

Rolnick, A. J., Weber, W. E. (1997), 'Money, Inflation, and Output under Fiat and Commodity Standards', Journal of Political Economy, 105(6): 1308-21.

Wimanda, R.E. (2010), 'Inflation and Monetary Policy Rules: Evidence from Indonesia', Doctoral Thesis, Loughborough University. 


\section{Appendix}

\begin{tabular}{|c|c|c|c|c|}
\hline & Coef & Std. Error & t-Statistic & Prob. \\
\hline $\begin{array}{l}\text { Constant } \\
\text { Inflation(-1) } \\
\text { Inflation(1) } \\
\text { Output Gap(-9) } \\
\text { Exchange Rate Dep(-1) } \\
\text { M1 Growth(-2) }<=9.84 \% \\
9.84 \%<\text { M1 Growth(-2)<=17.13\% } \\
17.13 \%<\text { M1 Growth(-2) } \\
\text { Dummy Crisis } \\
\text { Dummy Fuel } \\
\text { Dummy Fitri }\end{array}$ & $\begin{array}{l}-0.571 \\
0.689 \\
0.248 \\
0.052 \\
-0.045 \\
0.127 \\
0.057 \\
0.038 \\
1.219 \\
2.835 \\
0.543\end{array}$ & $\begin{array}{l}0.190 \\
0.0371 \\
0.052 \\
0.021 \\
0.009 \\
0.035 \\
0.018 \\
0.009 \\
0.508 \\
0.643 \\
0.206\end{array}$ & $\begin{array}{l}-3.000 \\
8.537 \\
4.751 \\
2.447 \\
-5.302 \\
3.502 \\
3.079 \\
3.977 \\
2.400 \\
4.406 \\
2.639\end{array}$ & $\begin{array}{l}0.003 \\
0.000 \\
0.000 \\
0.015 \\
0.000 \\
0.001 \\
0.002 \\
0.000 \\
0.017 \\
0.000 \\
0.009\end{array}$ \\
\hline $\begin{array}{l}\text { Adjusted R-squared } \\
\text { S.E. of regression } \\
\text { SSR }\end{array}$ & $\begin{array}{c}0.992 \\
1.047 \\
358.479\end{array}$ & & & \\
\hline
\end{tabular}

\begin{tabular}{|c|c|c|c|c|}
\hline & Coef & Std. Error & t-Statistic & Prob. \\
\hline $\begin{array}{l}\text { Constant } \\
\text { Inflation(-1) } \\
\text { Inflation(1) } \\
\text { Output Gap(-9) } \\
\text { Exchange Rate Dep(-1) } \\
\text { M1 Growth(-2) }<=4.93 \% \\
4.93 \%<\text { M1 Growth(-2)<= } 7.08 \% \\
7.08 \%<\text { M1 Growth(-2)<= } 9.84 \% \\
9.84 \%<\text { M1 Growth(-2) } \\
\text { Dummy Crisis } \\
\text { Dummy Fuel } \\
\text { Dummy Fitri }\end{array}$ & $\begin{array}{l}-0.387 \\
0.684 \\
0.256 \\
0.049 \\
-0.045 \\
0.085 \\
0.169 \\
0.085 \\
0.031 \\
1.116 \\
2.926 \\
0.600\end{array}$ & $\begin{array}{l}0.152 \\
0.037 \\
0.052 \\
0.021 \\
0.009 \\
0.077 \\
0.055 \\
0.030 \\
0.008 \\
0.498 \\
0.639 \\
0.203\end{array}$ & $\begin{array}{l}-2.549 \\
18.475 \\
4.972 \\
2.317 \\
-5.186 \\
1.097 \\
3.094 \\
2.848 \\
3.900 \\
2.242 \\
4.576 \\
2.963\end{array}$ & $\begin{array}{l}0.011 \\
0.000 \\
0.000 \\
0.021 \\
0.000 \\
0.273 \\
0.002 \\
0.005 \\
0.000 \\
0.026 \\
0.000 \\
0.003\end{array}$ \\
\hline $\begin{array}{l}\text { Adjusted R-squared } \\
\text { S.E. of regression } \\
\text { SSR }\end{array}$ & $\begin{array}{c}0.992 \\
1.034 \\
348.456\end{array}$ & & & \\
\hline
\end{tabular}

